Roni Wulansari, Karjuni Dt. Ma'anil Implementasi Kebijakan Rehabilitasi Rumah Tidak Layak Huni Menjadi Layak Huni di Kabupaten Pasaman Barat

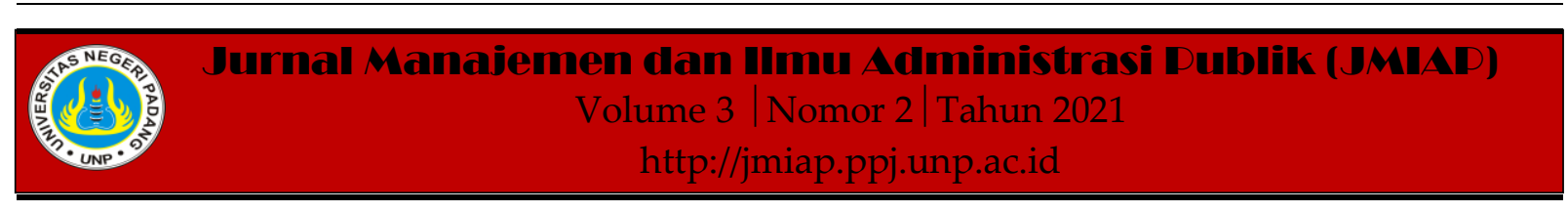

\title{
IMPLEMENTASI KEBIJAKAN REHABILITASI RUMAH TIDAK LAYAK HUNI MENJADI LAYAK HUNI DI KABUPATEN PASAMAN BARAT
}

\author{
Roni Wulansari ${ }^{1(a)}, K^{\text {Karjuni Dt. Ma'ani }}{ }^{2(b)}$ \\ ${ }^{1}$ Jurusan Ilmu Administrasi Negara, Universitas Negeri Padang \\ ${ }^{2}$ Jurusan Ilmu Administrasi Negara, Universitas Negeri Padang \\ ${ }^{a)}$ roniwulansari15042046@gmail.com, ${ }^{b}$ karjuni.dtmaani@ fis.unp.ac.id
}

\begin{abstract}
This study aims to determine the implementation of the policy of rehabilitating uninhabitable houses into habitable houses in west pasaman regency. This research was motivated by the seriousness of the government in meeting the basic needs of housing through improving the quality of houses, the problems raised were related to budget constraints and lack of socialization by the organizers to the community. To answer this problem, interviews were conducted with 5 sources. This research was conducted at the housing and settlement service of west pasaman regency. The tools used for data analysis were qualitative. According to the results of interviews conducted, the implementation of the rehabilitation policy for unfit for habitation in west pasaman regency has been implemented during 2017-2019 and continues until 2025. The number of houses that have been rehabilitated based on the decree of the regent of west Pasaman Regency is 475 housing units.

Keywords : Policy Implementation, Community Empowerment, RTLH

Corresponding author. Email.roniwulansari15042046@gmail.com

How to cite this article. Wulansari, R \& Ma'ani, K. (2021). Implementasi Kebijakan Rehabilitasi Rumah Tidak Layak Huni Menjadi Layak Huni di Kabupaten Pasaman Barat. Jurnal Manajemen dan Ilmu Administrasi Publik (JMIAP) Jurusan Ilmu Administrasi Negara Fakultas Ilmu Sosial Universitas Negeri Padang, Volume 3 (2), Hal. 163-171.

http://jmiap.ppj.unp.ac.id

Copyright $@ 2021$. Published by Labor Jurusan Ilmu Administrasi Negara FIS UNP, Padang
\end{abstract}


Roni Wulansari, Karjuni Dt. Ma'anil Implementasi Kebijakan Rehabilitasi Rumah Tidak Layak Huni Menjadi Layak Huni di Kabupaten Pasaman Barat

\section{PENDAHULUAN}

Rumah adalah tempat tinggal dan berlindung serta tempat yang digunakan untuk ketahanan hidup sesorang beserta keluarganya. Rumah yang layak yaitu unsur yang paling penting untuk menjalankan kehidupan bagi mereka yang menempatinya. Sedangkan memiliki rumah tidak layak menimbulkan rasa tidak aman karena dapat menyebabkan berbagai macam penyakit.

Dalam kehidupan bernegara, Pemerintah memiliki fungsi menyediakan kebutuhan dasar masyarakat terutama pada pemenuhan kebutuhan rumah layak huni. Pasaman Barat sebagai partisipan program RTLH Kementrian Pekerjaan Umum dan Perumahan Rakyat, memiliki angka kemiskinan yang cukup tinggi karena perekonomian dikuasai oleh perusahaan asing sehingga lahan untuk bertani bagi masyarakat semakin sempit akibatnya masyarakat menjadi buruh harian pada perusahaan pengelola perkebunan tersebut.

Untuk mengatasi masalah kemiskinan khususnya dalam peningkatan kualitas rumah layak huni Pemerintah Kabupaten Pasaman Barat menuangkan dalam (Peraturan Bupati Pasaman Barat No. 48 tahun 2017, n.d.), pada pasal 2 yakni RTLH dibentuk bertujuan meningkatkan kualitas RTLH menjadi layak huni yang pengerjaan nya dilaksanakan secara swadaya.

RTLH merupakan kegiatan membangun kembali rumah yang sudah ada sebelumnya yang bersifat tidak layak huni menjadi layak huni dan berkelanjutan. Program RTLH sangat membantu masyarakat untuk memenuhi kebutuhan papannya, masyarakat yang menerima bantuan pada umumnya bekerja sebagai petani yang hanya mampu memenuhi kebutuhan pangan bagi keluarganya. Kriteria orang yang mendapatkan program RTLH yaitu masyarakat yang berpenghasilan rendah dan tidak berpenghasilan tetap dengan membentuk suatu kelompok minimal 10 orang atau bisa diajukan secara perorangan. Pengerjaan rehabilitasi rumah dilakukan secara swakelola atau bergotong royong dalam waktu kurang lebih satu bulan dan diawasi langsung oleh pendamping pelaksana yang telah ditunjuk.

Adapun hasil finalisasi data rumah layak huni di Kabupaten Pasaman Barat pada tahun 2015 yaitu:

Tabel 1. Data Rumah Layak Huni dan Rumah Tidak Layak Huni (RTLH) Kabupaten Pasaman Barat Tahun 2015

\begin{tabular}{|c|l|c|c|c|}
\hline No & \multicolumn{1}{|c|}{ Kecamatan } & $\begin{array}{c}\text { Jumlah } \\
\text { Rumah }\end{array}$ & RTLH & $\begin{array}{c}\text { Layak } \\
\text { Huni }\end{array}$ \\
\hline 1 & Koto Balingka & 5.976 & 118 & 5.918 \\
\hline 2 & Sei Beremas & 2.883 & 73 & 2.914 \\
\hline 3 & Talamau & 4.308 & 593 & 3.795 \\
\hline 4 & Ranah Batahan & 7.050 & 473 & 6.597 \\
\hline 5 & Gunung Tuleh & 5.658 & 326 & 5.322 \\
\hline 6 & Lembah Melintang & 9.578 & 73 & 9.505 \\
\hline 7 & Sei Aur & 7.308 & 634 & 6.754 \\
\hline 8 & SasakRanahPasisie & 2.937 & 326 & 2.622 \\
\hline 9 & Kinali & 6.422 & 638 & 4.844 \\
\hline 10 & Luhak Nan Duo & 8.523 & 137 & 8.446 \\
\hline 11 & Pasaman & 15.025 & 499 & 14586 \\
\hline \multicolumn{2}{|c|}{ Jumlah } & 75.688 & 3.890 & 72.302 \\
\hline
\end{tabular}

Berdasarkan tabel diatas, rumah tidak layak huni di Kabupaten Pasaman Barat mencapai 3.890 rumah. Jumlah rumah tidak layak huni terbanyak berada pada kecamatan Kinali dengan jumlah 638 unit sedangkan jumlah rumah tidak layak huni paling sedikit adalah Kecamatan Sungai Beremas dan Kecamatan Lembah Melintang masing-masingnya 73 unit. Pembangunan Rehabilitasi Rumah Tidak Layak Huni dilaksanakan secara swadaya kelola atau pemberdayaan masyarakat.

Pelaksanaan RTLH di kabupaten Pasaman Barat memiliki beberapa keterbatasan dan permasalahan diantaranya:

1. Keterbatasan anggaran, Dalam pelaksanaan RTLH nilai uang Rp. 15.000.000 tidak langsung diserahkan kepada masyarakat penerima bantuan. Konsultan perumahan swadaya 
menyerahkan kepada ketua kelompok dan ada yang langsung kepada masyarakat penerima bantuan bukan berupa uang tunai tetapi berbentuk bahan yang dibutuhkan untuk pembangunan, adapun bahan bangunan yang disediakan seperti batu kali, pasir, semen, papan, batu batako, kayu-kayu (termasuk konsen pintu dan jendela), atap rumah, dan paku.

2. Kurangnya pengetahuan masyarakat miskin terkait pemberian bantuan RTLH di Kabupaten Pasaman Barat menjadi salah satu masalah dalam implementasi program tersebut. Program ini dilaksanakan berdasarkan data masyarakat miskin pada tahun 2015 yang ada pada BPS dan Dinas Sosial. Proses pengajuan penerima bantuan berdasarkan data yang ada pada masing-masing nagari tanpa melakukan pendataan survei ulang, sehingga data tersebut kurang akurat karena jumlah masyarakat miskin di masing-masing nagari bisa tertambah atau berkurang dalam setiap tahunya. Berdasarkan data yang diajukan, sebelum menetapkan calon penerima bantuan RTLH pihak Dinas melakukan pendataan dan survei ulang untuk mendapatkan data yang akurat bagi masyarakat yang memiliki rumah jauh dari kata layak.

\section{TINJAUAN PUSTAKA}

\section{Teori Implementasi Kebijakan}

Implementasi kebijakan adalah serangkaian perbuatan suatu individu, lembaga pemerintahan atau swasta dengan sarana pendukung berdasarkan aturan yang telah ditetapkan untuk mencapai sebuah tujuan. Implementasi berkenaan beragam aktivitas yang dipusatkan untuk terlaksananya suatu program. Keadaan ini dibutuhkan sebuah tata kelola untuk menata atau menyusun kebijakan, menginterprestasikan serta menjalankan strategi yang ditentukan (Pasalong, 2010).

Pelaksanaan strategi yakni sistem transformasi regulasi menjadi tindakan, oleh karena itu dalam praktiknya, akibat pengaruh berbagai relevansi, pelaksanaan strategi bisa dikatakan sebagai sistem politik yang berbelit-belit (Agustino, 2016).

\section{Model Implementasi Kebijakan Edward III George C. Edwad III (1984)}

a) Komunikasi

Dalam sebuah implementasi kebijakan komunikasi diartikan sebagai penentu keberhasilan suatu tujuan dari sebuah kebijakan. Komunikasi dapat berjalan dengan baik apabila para pembuat keputusan lebih efektif dan mengerti apa yang mereka kerjakan. Untuk mengukur keberhasilan komunikasi terdapat tiga indikator yang dapat digunakan yaitu:

1. Transmisi yaitu suatu penyaluran informasi yang dapat dimengerti agar terhindar dari kesalahan interpertasi dalam mengimplementasikannya.

2. Kejelasan berarti dalam penyampaikan suatu kebijakan komunikator sebaiknya menggunakan komunikasi yang jelas, tidak membingungkan dan mudah diterima oleh para pelaksana.

3. Konsistensi berarti intruksi yang diberikan harus diterapkan sesuai arahan agar tidak terjadi kesalahan dalam melaksanakanya.

b) Sumber Daya

Sumber daya merupakan faktor yang sangat penting dalam melaksanakan kebijakan, tanpa sumber daya sebuah program tidak berjalan dengan baik. Sumber daya dibedakan menjadi empat yaitu:

1. Adanya sumber daya manusia yang memadai, terampil, dan pofesional.

2. Tersedia Informasi mengenai cara pelaksanaan kebijakan, peraturan, dan regulasi.

3. Adanya wewenang yang jelas.

4. Tersedia fasilitas pendukung.

c) Disposisi

Disposisi merupakan perilaku dan karakteristik implementor dalam pelaksanaan kebijakan yang memiliki komitmen dan kejujuran. Implementor yang berkomitmen dan jujur akan berdampak 
Roni Wulansari, Karjuni Dt. Ma'anil Implementasi Kebijakan Rehabilitasi Rumah Tidak Layak Huni Menjadi Layak Huni di Kabupaten Pasaman Barat

baik dan kecil kemungkinan terjadi kesalahan dalam menjalankanya.

\section{d) Struktur birokrasi}

Stuktur birokrasi adalah tata urut pelaksanan administrasi dalam pengelolaan kegiatan. Dalam pelaksanaanya berdasarkan Standar Operating Prosedures (SOP) maka pelaksanaan tugas diberikan tanggungjawab dan kewenangan menurut tugas dan fungsi yang saling berkoordinasi.

\section{Model Implementasi Kebijakan Donald Van Metter dan Carl Van Horn}

Pendapat Van Meter dan Van Horn (2017: 133) dalam Agustino, teori tersebut menyatakan bahwa terdapat enam variabel yang memiliki dampak pada kapasitas strategi, yakni:

a) Skala serta Sasaran Strategi

Jika skala dan sasaran strategi pragmatis, maka kesuksesan pelaksanaan strategi bisa diukur.

b) Sumber daya

Kesuksesan sistem pelaksanaan strategi amat bersandar pada kapabilitas untuk menggunakan kapasitas yang ada, antara lain human resource dan non-human resource.

c) Individualitas Biro Penyelenggara

Variabel ini merangkap pola otoritas, aturan-aturan, dan paradigma korelasi yang ada pada otoritas, yang semuanya itu akan memengaruhi pelaksanaan satu program.

d) Sikap/Kecenderungan (Disposition) sentral eksekutif

Aksi penolakan atau pengakuan dari lembaga eksekutif akan amat berdampak pada sukses atau gagalnya pelaksanaan garis haluan publik. Keadaan ini amat bisa jadi timbul oleh karena strategi yang dijalankan bukanlah buah perumusan oknum-oknum yang terpaut secara langsung pada strategi yang memahami betul masalah yang mereka rasakan.

e) Dialog Antarorganisasi dan Gerakan Eksekutif

Penyelarasan adalah metode yang efektif untuk melaksanakan kebijakan publik. Semakin baik dialog dan penyelarasan antara golongan-golongan yang terjun dalam cara pelaksanaan, maka dapat diasumsikan kesalahannya akan semakin kecil.

f) Lingkungan Ekonomi, Sosial, dan Politik

Memperhatikan sampai dimana kontribusi lingkungan luar terhadap kesuksesan kebijakan publik yang ditetapkan.

\section{Model Implementasi Kebijakan Merilee S. Grindle}

Grindle memublikasikan bentuk pelaksanaan sebagai teknik politik dan tata kelola (Header, 2008: 7). Bentuk ini memvisualisasikan cara pemungutan ketetapan yang dijalankan oleh peserta yang berbeda, dan hasil akhirnya tergantung pada materi perencanaan yang direalisasikan dan interaksi para pengambil keputusan dalam lingkungan administrasi dan politik. Proses politik dapat diwujudkan dengan proses pengambilan keputusan yang melibatkan berbagai partisipan kebijakan, dan proses administrasi dapat diwujudkan dengan proses perilaku administrasi umum yang dapat diinvestigasi pada tingkat perencanaan tertentu.

Dalam teori Grindle memandang bahwa sesuatu implementasi sangat ditentukan oleh isi kebijakan dan konteks implementasinya. Grindle (dalam Taher, 2016:74) menyatakan kalau cara pelaksanaan kebijakan hanya bisa dimulai bila skema-skema serta bidikan-bidikan yang awal sudah diperinci, strategi-strategi tindakan sudah diatur, dan beberapa dana sudah diberikan agar menciptakan skemaskema serta bidikan-bidikan tersebut. Sementara pendapat Grindle (dalam Agustino, 2017: 142-145), kesuksesan pelaksanaan kebijakan publik bisa dihitung dari teknik penggapaian hasil (yakni apakah sasaran yang ingin dicapai tercapai).

\section{Model Implementasi Kebijakan Brian W. Hogwood dan Lewis A. Gunn}

Pendapat Hogwood dan Gun (1978) dalam Mulyadi (2015:73-74), agar bisa mengimplementasikan stategi dengan cara 
Roni Wulansari, Karjuni Dt. Ma'ani| Implementasi Kebijakan Rehabilitasi Rumah Tidak Layak Huni Menjadi Layak Huni di Kabupaten Pasaman Barat

lengkpa (perfect implementation) maka dibutuhkan sejumlah persyaratan tertentu. ketetapan itu adalah yakni:

a) Situasi luar yang dijumpai lembaga/badan eksekutif tidak akan menyebabkan hambatan.gangguan yang fatal.

b) Punya cukup waktu dan sumber daya.

c) Kombinasi kapasitas yang dibutuhkan sudah tersedia.

d) Strategi yang akan dijalankan diasaskan pada sebab-akibat yang dapat diandalkan.

e) Kausalitasnya langsung, dan hanya ada beberapa tautan dalam rantai asosiasi.

f) Saling ketergantungan harus kecil. Pemahaman dan konsensus yang mendalam tentang sasaran.

g) Buat daftar tugas dan tempatkan dalam urutan yang benar..

h) Komunikasi dan penyelarasan yang lengkap.

i) Mereka yang berkuasa dapat menuntut dan memperoleh kepatuhan yang sempurna.

\section{METODE PENELITIAN}

Pendekatan yang peneliti gunakan dalam penelitian ini yaitu pendekatan kualitatif desktiptif. Lokasi penelitian di Dinas Perumahan dan Kawasan Permukiman Pasaman Barat. Data yang dipakai pada kajian ini yakni data mentah dan data pembantu. Akumulasi data dengan cara wawancara, pengamatan dan dokumentasi dan uji keabsahan data menggunakan teknik triangulasi. Sedangkan teknik analisis data dilakukan dengan pengumpulan data, reduksi data, penyajian data. dan penarikan kesimpulan.

\section{HASIL DAN PEMBAHASAN}

Penelitian ini melihat sejauhmana Kebijakan rehabilitasi rumah tidak layak huni menjadi rumah layak huni di Kabupaten Pasaman Barat dilaksanakan. Teori yang dipakai serta dilakukan pengembangan sesuai kebutuhan peneliti yaitu teori George C. Edward terdapat beberapa indikator yaitu komunikasi, sumber daya, disposisi, dan struktur birokrasi.

\section{Tabel 2. Jumlah Penerima Bantuan RTLH Tahun Anggaran 2017-2019}

\begin{tabular}{|c|c|c|c|c|}
\hline \multirow[t]{2}{*}{ No } & \multirow[t]{2}{*}{ Kecamatan } & \multicolumn{3}{|c|}{$\begin{array}{c}\text { Jumlah } \\
\text { Pertahun }\end{array}$} \\
\hline & & 2017 & 2018 & 2019 \\
\hline 1 & Koto Balingka & 15 & 60 & 8 \\
\hline 2 & Sei Beremas & 14 & 40 & 8 \\
\hline 3 & Talamau & 7 & - & 8 \\
\hline 4 & Ranah Batahan & 14 & 60 & 20 \\
\hline 5 & Gunung Tuleh & 24 & - & 38 \\
\hline 6 & $\begin{array}{l}\text { Lembah } \\
\text { Melintang }\end{array}$ & 7 & - & 45 \\
\hline 7 & Sei Aur & 3 & 20 & - \\
\hline 8 & $\begin{array}{c}\text { Sasak Ranah } \\
\text { Pasisie }\end{array}$ & - & - & 20 \\
\hline 9 & Kinali & - & - & 20 \\
\hline 10 & Luhak Nan Duo & - & - & - \\
\hline 11 & Pasaman & 15 & - & 23 \\
\hline \multirow{2}{*}{\multicolumn{2}{|c|}{\begin{tabular}{|c|} 
Jumlah \\
Total \\
\end{tabular}}} & 99 & 180 & 196 \\
\hline & & & & 475 \\
\hline
\end{tabular}

Sumber: Dinas Perumahan dan Kawasan

Permukiman Kabupaten Pasaman Barat

Kecamatan yang tidak mendapatkan bantuan yaitu Kecamatan Luhak Nan Duo, Pemerintah Kabupaten Pasaman Barat melalui Dinas Perumahan dan Kawasan Permukiman telah mengajukan data calon penerima bantuan RTLH sebanyak 137 unit rumah tidak layak huni pada tahun 2016. Data tersebut terlebih dahulu kami kirim ke Provinsi selanjutnya, oleh Pemerintah Provinsi dikirimkan ke Kementrian PUPR. Pada saat pihak dari Kementrian bersama Tenaga Fasilitator Lapangan survei ke Kecamatan tersebut untuk memvalidasi data. Ditemukan bahwa rumah yang sebanyak 137 unit yang sebagian tergolong rumah layak huni dan tidak termasuk dalam kriteria calon penerima bantuan. Penulis menemukan bahwa di Kecamatan Luhak Nan Duo banyak masyarakat yang mendapatkan bantuan bedah rumah dari Dinas Sosial tepatnya di Jorong Simpang Tiga dan Jorong Mahakarya pada tahun 2016. 
Roni Wulansari, Karjuni Dt. Ma'anil Implementasi Kebijakan Rehabilitasi Rumah Tidak Layak Huni Menjadi Layak Huni di Kabupaten Pasaman Barat

Tabel 3. Pembiayaan

\begin{tabular}{|c|c|l|}
\hline No & Tahun & Pembiayaan (Rp) \\
\hline 1 & 2017 & 15.000 .000 \\
\hline 2 & 2018 & 15.000 .000 \\
\hline 3 & 2019 & 17.500 .000 \\
\hline
\end{tabular}

Anggaran program RTLH bersumber dari APBN dalam bentuk DAK yang dikelola oleh Kabupaten berasaskan Keputusan Menteri Pekerjaan Umum dan Perumahan Rakyat.

Dalam proses penyaluran bantuan kegiatan RTLH terdiri dari dua bentuk bantuan yaitu bentuk uang dan barang. Pada tahun 2017 pelaksanaan RTLH di Kabupaten Pasaman Barat pelaksanaanya disediakan barang berupa bahan bangunan untuk rumah oleh pelaksana teknis senilai uang yang tersedia dengan dibuktikan faktur pembelian barang. Dalam pemanfaatan bantuan, penerima bantuan setelah menerima berupa bahan bangunan, penerima bantuan melakukan kegiatan rehabilitasi rumah selaras dengan rencana teknis. Setelah implementasi selesai, penerima bantuan wajib bertanggung jawab atas fisik pelaksanaan rehabilitasi rumah dan mesti bertanggung jawab memberikan informasi pemakaian bahan bangunan dilengkapi foto rumah.

Pada tahun 2018 dan 2019 pelaksanaan kebijakan rehabilitasi rumah tidak layak huni dilaksanakan dalam bentuk penyaluran berupa uang yang ditransfer langsung dari Bank Nagari ke rekening penerima bantuan. Dalam pemanfaatan bantuan dana terdiri dari dua (2) 50\% dari nilai bantuan dengan mentransfer ke toko penyedia bahan bangunan yang ditentukan sebelumnya, bantuan akan digunakan saat membayar. Jika realisasi kemajuan perbaikan rumah minimal $30 \%$ atau dana tahap pertama sudah habis dan perbaikan rumah sudah dilaksanakan dan bahan bangunan tahap kedua sudah diterima, maka dana bantuan tahap kedua dapat digunakan 50\%. Setelah pelaksanaan selesai, penerima harus menyerahkan laporan pamakaian dana bantuan kepada penanggung jawab layanan, bersama dengan foto rumah.

\section{a) Komunikasi}

Pelaksanakan program RTLH ditujukan pada masyarakat miskin dan masyarakat berpenghasilan rendah, terlebih dahulu diadakan sosialisasi agar masyarakat memahami apa maksud dan tujuan dari program tersebut. Penyampaian sosialisasi dilakukan dengan cara Dinas Perumahan dan Kawasan Permukiman memberitahukan kepada wali nagari untuk mengundang calon penerima bantuan yang ditetapkan oleh Kementrian PUPR dan sebagai narasumber yaitu Pelaksana Teknis dan Tenaga Fasilitator Lapangan bertempat di Kantor Wali Nagari.

Pelaksanaan sosialisasi RTLH tidak secara langsung kepada masyarakat, sesuai SOP RTLH dari Kementrian PUPR bahwa sosialisasi hanya ditujukan pada masyarakat yang terdaftar sebagai penerima bantuan. Dalam pelaksanaan komunikasi calon penerima diminta melengkapi persyaratan dan membuat proposal pengajuan yang dibantu oleh Tenaga Fasilitator Lapangan.

b) Sumber Daya

Sebuah kebijakan tidak akan berjalan efektif apabila implementor tidak mencukupi atau tidak kompeten dibidangnya (Agustino, 2016). Dalam pelaksanaan RTLH Pasaman Barat yang menjadi sumber daya manusia yaitu bidang perumahan swadaya atau rumah khusus memiliki staf yang bertugas sebagai pendamping pada pelaksana rehabilitasi rumah tidak layak huni sebanayak tiga orang.

Kegiatan RTLH Dinas Perumahan dan Kawasan Permukiman Pasaman Barat memiliki sumber daya manusia yang memiliki keterampilan dan skil serta menguasai teknik pembangunan untuk melaksanakan kebijakan tersebut, sehingga dalam pelaksanaanya terselesaikan dengan baik dan tepat waktu. Dalam pelaksanaanya 
Roni Wulansari, Karjuni Dt. Ma'anil Implementasi Kebijakan Rehabilitasi Rumah Tidak Layak Huni Menjadi Layak Huni di Kabupaten Pasaman Barat

Dinas Perumahan dan Kawasan

Permukiman bekerja secara mandiri tanpa pengaruh pihak lain dalam pelaksaan kegiatan tersebut. Tetapi, melibatkan Tokoh Masyarakat (seperti LSM) sebagai pendamping pelaksanaan, Jorong dan Wali Nagari.

Dalam pelaksanaan sumber daya tidak lepas dari fasilitas pendukung sehingga implementasi program akan berjalan sempurna. Fasilitas dalam kegiatan RTLH memadai terdapat ada dua yaitu: Bank Nagari sebagai fasilitas bagi masyarakat yang menerima bantuan berupa uang dan Fasilitas Toko Bangunan yang ditetapkan Pemerintah Pasaman Barat sebagai penyediaan bahan bangunan untuk masyarakat penerima bantuan berupa barang.

\section{c) Disposisi}

Perilaku atau karakterisrik yang implementor dalam mewujudkan implementasi kebijakan sesuai sasaran atau tujuan yang telah ditetapkan. Komitmen dan kejujuran adalah karakter yang dimiliki oleh pelaksana kebijakan (Agustino, 2016). Dalam pelaksanaan RTLH di Pasaman Barat, bahwa karakteristik yang dimiliki oleh implementor sudah cukup baik. Hal ini terlihat dalam komitmen serta kejujuran pihak penyelenggara dalam melaksanakan tugasnya dan selalu berpedoman dengan Peraturan Bupati Pasaman Barat No 48 Tahun 2017.

Sikap pendamping dalam kegiatan memberikan penjelasan sangat memuaskan dan mudah di mengerti, sabar, santun, dan tegas dalam mengambil keputusan, setiap ada masalah yang kurang dipahami oleh masyarakat yang merasa kurang puas atas pelaksanaan kegiata tersebut. Contohnya disiplin waktu dan disiplin dalam penggunaan bahan yang tersedia.

\section{d) Struktur Birokrasi}

George C. Edrward III dalam Agustino (2017) dalam mengimplementasikan kebijakan struktur orgranisasi menjadi aspek yang sangat penting. Dalam pelaksanaanya berdasarkan Standar Operating Prosedures (SOP) maka pelaksana tugas diberikan tanggungjawab dan kewenangan menurut tugas dan fungsi yang saling berkoordinasi.

Pelaksanaan RTLH oleh Dinas Perumahan dan Kawasan Permukiman Kabupaten Pasaman Barat tidak membuat Standart Operasional Procedure (SOP) sendiri tetapi menggunakan Standart Operasional Procedure (SOP) dari Kementerian PUPR Republik Indonesia yang dituangkan dalam Peraturan Menteri PUPR.

\section{Kendala dalam Implementasi Kebijakan Rehabilitasi Rumah Tidak Layak Huni Menjadi Rumah Layak Huni di Kabupaten Pasaman Barat}

Implementasi program RTLH bertujuan untuk peningkatan kualitas rumah tidak layak huni menjadi rumah layak huni bagi masyarakat miskin agar memiliki rumah yang sehat, nyaman, dan berkelanjutan. Namun dalam penerapanya, tentu tengah ada masalah atau halangan-halangan yang dirasakan, baik itu pemerintah atau komunitas itu sendiri. Masalah adalah segala hambatan atau halangan yang dihadapi suatu organisasi dalam menggapai sasaran yang ingin digapai.

Gow dan Morss dalam Pasolong (2010;59), mengelompokan hambatan implementasi kebijakan publik menjadi dua faktor yaitu: faktor internal dan faktor eksternal. Faktor internal adalah hambatan yang terdapat dalam lingkungan pelaksana kebijakan. Sedangkan faktor eksternal adalah hambatan yang terdapat dari luar lingkungan pelaksana kebijakan.

Berdasarkan temuan penulis, adapun hambatan dalam mengimplementasikan kebijakan RTLH di Kabupaten Pasaman Barat yaitu sebagai berikut:

a) Faktor Internal, berasal dari dalam organisasi pada Dinas Perumahan dan Kawasan Permukiman. Hambatan yang dihadapi yaitu lambatnya pencairan anggaran dari Pemerintahan Pusat, sehingga pelaksanaan pengerjaan 
rehabilitasi rumah menjadi terkendala. Akibatnya jadwal pelaksanaan tidak sesuai dengan jadwal yang telah ditetapkan. Sehingga diperlukan adanya upaya untuk mengatasi kendala internal dalam mengimplementasikan kebijakan RTLH di Kabupaten Pasaman Barat.

b) Faktor Eksternal, yaitu hambatan yang dihadapi dari luar Dinas Perumahan dan Kawasan Permukiman. Adapun kendala yang dihadapi dalam pelaksanaan RTLH yaitu berasal dari kelompok masyarakat yang merasa kurang puas terhadap penunjukan calon penerima bantuan yang tidak mendapatkan bantuan. Sehingga hal ini menyebabkan terkendalanya pelaksanaan RTLH di Kabupaten Pasaman Barat.

\section{Upaya Yang Dilakukan Dalam Memaksimalkan Implementasikan Kebijakan Rehabilitasi Rumah Tidak Layak Huni Menjadi Rumah Layak Huni Di Kabupaten Pasaman Barat}

Tentunya menyingkirkan masalah yang dihadapi dan upaya mengatasi kendala yang ada harus seimbang. Dalam mengimplementasikan kebijakan RTLH di Kabupaten Pasaman Barat tentunya terdapat upaya yang dilaksanakan oleh Dinas Perumahan serta Kawasan Permukiman untuk mengatasi kendala yang dihadapi. Berdasarkan temuan penulis, adapun upaya yang dilakukan oleh Dinas Perumahan dan Kawasan Permukiman dalam mengatasi kendala keterlambatan pencairan dana bantuan RTLH dari Pemerintah Pusat, untuk mengatasi kendala tersebut Dinas Perumahan dan Kawasan Permukiman merubah jadwal pelaksanaan rehabilitasi rumah tidak layak huni yang awalnya dilaksanakan pada triwulan tiga dan empat, dirubah menjadi triwulan ke dua agar tidak terkendala oleh anggaran perubaan. Hal ini dilakukan untuk mempercepat pelaksanaan rehabilitasi rumah tidak layak huni menjadi layak huni. Sehingga nantinya pelaksanaan RTLH bisa berjalan dengan lancar dan efektif.
Selain itu, Dinas Perumahan dan Kawasan Permukiman berupaya untuk mengatasi kendala terkait ketidakpuasan masyarakat dalam penetapan calon penerima bantuan. Situasi ini Dinas Perumahan dan Kawasan Permukiman melaksanakan verifikasi ulang data yang diajukan oleh Wali Nagari sebagai calon penerima bantuan dan melaksanakan identifikasi lokasi untuk memvalidasi data calon penerima bantuan. Hal ini dilakukan untuk kelancaran pelaksanaan kegiatan rehabilitasi rumah tidak layak huni, sehingga mempercepat verifikasi dan validasi data untuk mengajukan calon penerima bantuan dan menerbitkan Surat Keputusan Bupati.

\section{PENUTUP}

Dari hasil kajian deskripsi yang dilakukan, tentang Implementasi Kebijakan Rehabilitasi Rumah Tidak Layak Huni Menjadi Rumah Layak Huni di Kabupaten Pasaman Barat, maka dapat disimpulkan bahwa:

1. Implementasi Kebijakan Rehabilitasi Rumah Tidak Layak Huni Menjadi Layak Huni di Kabupaten Pasaman Barat dalam pelaksanaanya sudah berjalan dengan baik dan berkelanjutan. Dalam proses pengajuan calon penerima bantuan diajukan oleh Dinas Perumahan dan Kawasan Permukiman melalui Pemerintah Propinsi. Selanjutnya data tersebut dikirim ke Kementrian Pekerjaan Umum dan Perumahan Rakyat. Sosialisasi dilakukan dengan cara mengundang calon penerima bantuan yang telah ditetapkan oleh Kementrian melalui Wali Nagari. Namum, dalam pelaksanaanya masih terdapat beberapa masalah diantaranya anggaran yang disediakan Pemerintah belum mencukupi. Sedangkan prosedur pelaksanaan kebijakan RTLH Dinas Perumahan dan Kawasan Permukiman telah melaksanakan kegiatan tersebut sesuai dengan SOP yang telah ditetapkan. 
Roni Wulansari, Karjuni Dt. Ma'anil Implementasi Kebijakan Rehabilitasi Rumah Tidak Layak Huni Menjadi Layak Huni di Kabupaten Pasaman Barat

2. Faktor yang mempengaruhi Implementasi Kebijakan Rehabilitasi Rumah Tidak Layak Huni Menjadi Layak Huni di Kabupaten Pasaman Barat, terdiri dari dua aspek yakni aspek dalam serta aspek luar. Pertama internal yakni lambatnya pencairan anggaran dari Pemeritah Pusat sedangkan yang kedua faktor eksternal yaitu adanya beberapa masyarakat yang merasa tidak puas terhadap penetapan calon penerima bantuan.

3. Upaya yang dilakukan Dinas Perumahan dan Kawasan Permukiman untuk mengatasi kendala yaitu dengan mempercepat jadwal implementasi tindakan rehabilitasi rumah tidak layak huni menjadi Triwulan ke dua dan melakukan verifikasi ulang data yang diajukan oleh Wali Nagari sebagai calon penerima bantuan dan melaksanakan identifikasi lokasi calon penerima bantuan untuk menvalidasi data.

\section{DAFTAR KEPUSTAKAAN}

Agustino, Leo. 2016. Dasar-dasar Kebijakan Publik. Bandung : Alfabeta.

Moleong, Lexy J. 2010. Metode Penelitian Kualitaif. Bandung: PT Remaja Rosdakarya.

Pasolong, Harbani. 2010. Teori Administrasi Publik. Bandung: Alfabeta.

Undang-undang Republik Indonesia Nomor 1 Tahun 2011 tentang Perumahan dan Kawasan Pemukiman.

Peraturan Menteri Pekerjaan Umum dan Perumahan Rakyat Republik Indonesia No 13/PRT/M/2016 tentang Bantuan Stimulan Perumahan Swadaya.

Peraturan Bupati Pasaman Barat Nomor 48 Tahun 2017 tentang Bantuan Stimulan Perumahan Swadaya.
Saputra, N., \& Mulia, R. A. (2020). Kontribusi Kompensasi Dan Motivasi Kerja Terhadap Kepuasan Kerja Pegawai Di Dinas Pendidikan Dan Kebudayaan Kabupaten Agam. Ensiklopedia Sosial Review, 2(1).

Sugiyono. 2016. Memahami Penelitian Kualitatif. Bandung: Alfabeta. 